\section{Mathematics Learning Through the Lens of Language Acquisition}

\author{
Michael J. Bossé a Anass Bayagab, Catherine Fountainc, \\ Erica Slate Youngd, Ashley DeMarte
}

$\begin{array}{ll}\text { Received: } & 24 \text { April } 2019 \\ \text { Revised: } \quad 23 \text { Semptember } 2019 \\ \text { Accepted: } \quad 26 \text { September } 2019 \\ \text { ISSN: 1307-9298 } \\ \text { Copyright (C) IEJEE } \\ \text { www.iejee.com }\end{array}$

DOI: 10.26822/iejee.2019155342

\begin{abstract}
Previous theoretical research has revealed conceptual similarities among a number of mathematical learning theories and theories regarding language acquisition. This intersection of ideas led to a novel framework defining four stages of mathematical learning: Receiving, Replicating, Negotiating Meaning, and Producing. Through qualitative research methods and transcripts of student communication and work, this study empirically investigates this theoretical construct. The findings herein demonstrate that this construct is helpful in characterizing where students are in the process of learning mathematics and how to help them attain the next level in the stages of learning.
\end{abstract}

Keywords: Mathematics learning; Mathematics education; Language acquisition

\section{Introduction}

Research in language acquisition and the learning of mathematics continue to evolve. Recently, these two realms have intersected and mathematics learning has been shown to share similarities with language acquisition. In investigating the intersection of learning theories from mathematics and language acquisition, Bossé, et al. (2018a) and Bossé, Ringler, Bayaga, Fountain, and Slate Young (2018b) have proposed the Math Acquisition Framework, a multistage theory of mathematical learning with potentially far reaching ramifications for education. The stages in this framework include: Receiving, Replicating, Negotiating Meaning, and Producing. The Mathematics Acquisition framework was first proposed (Bossé, et al., 2018b) and then applied in the context of elementary and middle grades fraction learning (Bossé et al., 2018a). There remains a need to empirically apply this construct to further investigate student understanding and learning regarding other fields of mathematics and generally across mathematics. In this qualitative study, we employ the framework to investigate student mathematical understanding in a number of mathematical contents. Specifically, we examine student understanding in topics such as number theory (prime numbers), graphical representations, word problem, graphical analysis of asymptotes, and combinatorics. The goal of this study is to simultaneously investigate the framework in question and see what additional insights it provides to the assessment of student mathematical learning.

\section{Background}

While research in language acquisition and mathematical learning has developed along mostly distinct trajectories, extant studies examine the associations between linguistic and mathematical literacy (Thompson \& Rubenstein, 2014) and the functions of language in the math classroom (Moschkovich, 2005). However, few investigations have considered parallels between language acquisition and mathematical learning. To this end, Bossé et al. (2018a) and Bossé et al. (2018b) have proposed links between language acquisition and mathematical learning. To investigate and apply the framework they developed, background literature must be considered. This section briefly examines a number of fields of research connected to the Math Acquisition Framework that is later examined. A more thorough literature review and argumentation surrounding the selection of frameworks employed can be found in Bossé et al. (2018b). It is important to note that the mathematics and language learning frameworks employed in the development of the Math Acquisition Framework are far from exhaustive. Indeed, countless other frameworks could be investigated - to the extent that one could become paralyzed by the sheer volume of options. Thus, constraints were necessarily imposed in the initial development of the Math Acquisition Framework and these constraints have been maintained through following articles and studies employing the framework.

\section{Language Acquisition}

Within linguistics it is generally thought that the acquisition of language in childhood should be examined as a process entirely separate from other forms of more conscious learning (Chomsky, 1965; Lenneberg, 1967, 1975), though it is less clear that this is true for language acquisition outside of childhood, commonly called second language acquisition. We contend that even if the processes are not entirely parallel, examining what we know about language acquisition can help to explain several observable phenomena in mathematical learning. The theories of language acquisition utilized in

\footnotetext{
${ }^{a}$ Corresponding Author; Michael J. Bossé, Distinguished Professor of Mathematics Education, Department of Mathematical Sciences, Appalachian State University, Boone, NC, USA E-mail: bossemj@appstate.edu; Office phone: (828) 262-2862.

b Anass Bayaga, Research Professor, Department of Mathematics, Science \& Technology Education (MSTE), University of Zululand, and University of Cape Town, South Africa E-mail: bayagaa@unizulu.ac.za.

Catherine Fountain, Professor and Graduate Program Director, Department of Languages, Literatures \& Cultures, Appalachian State University, Boone, NC, USA E-mail: fountainca@appstate.edu.

Erica Slate Young, Assistant Professor, Department of Mathematical Sciences, Appalachian State University, Boone, NC, USA

E-mail: slateer@appstate.edu.

e Ashley DeMarte, Graduate Student, Department of Mathematical Sciences, Appalachian State University, Boone, NC, USA

E-mail: demarteam@appstate.edu.
} 
the present analysis primarily include the frameworks of Krashen (1977, 1982) and Cummins (1979, 1984, 1991).

Input, Output and Interlanguage. As a foundational Ianguage acquisition framework, Krashen's Monitor Mode (Krashen, 1977, 1982) makes a distinction between language learning (conscious learning occurring in the language learning classroom) and language acquisition (naturalistic acquisition through environmental interaction) and argues that the two can occur simultaneously. Krashen considers the conscious learning to be a sort of "monitor" that mediates unconscious processes of acquisition. Krashen also highlights the importance of what he calls "comprehensible input" in the language to be acquired: language that students are able to understand, but that is slightly beyond their current level of production. He argues for a "silent period" through which language learners often progress, where they are more focused on listening, understanding, and processing language rather than producing it.

Swain (1985) proposes that production of language is necessary for acquisition and that language learners experience "comprehensible output", where they notice gaps in their own production and cannot adequately articulate ideas they hold in their minds (Swain \& Lapkin, 1995) The idiosyncratic roles of comprehension (or input) and production (or output) lead to the notion that language learners develop and practice a distinctive set of unique and constantly evolving linguistic codes, called an "interlanguage" (Selinker 1972, 1992).

Cummins' Model. Cummins' framework of second language acquisition (Cummins, 1979, 1984, 1991) principally describes the process of second language acquisition by English language learners who are native speakers of non-English languages and are being integrated into an English-language school environment. Cummins' framework distinguishes between everyday communicative language skills called Basic Interpersonal Communication Skills (BICS) and Cognitive Academic Language Proficiency (CALP), the more specific linguistic skills that are needed for academic success in a second-language school environment. Cummins notes that a key distinction between these two types of language skills is that BICS is somewhat cognitively undemanding, whereas CALP is much more cognitively demanding.

Cummins' framework also proposes the Linguistic Interdependence Theory, better known as Common Underlying Proficiency (CUP), stating that, when learning a second language, experience and learning in either language will lead to increased competence underlying both languages. According to CUP, transferable skills, learning, and knowledge in any language facilitate the learning of the second language. This agrees with a large body of research on third language acquisition that argues that there is no need to re-teach academic concepts in other languages because knowledge is transferable between languages (Cabrelli Amaro, Flynn, \& Rothman, 2012).

\section{Mathematical Learning Theories}

Van Hiele Model. Van Hiele (1986) posits five sequentia levels in the process of geometric learning (Blomert \& Froyen, 2010). In Visualization, students recognize figures but do not recognize properties of these figures. In Analysis, students analyze components of figures, but cannot explain interrelationships between and properties among figures. Informal Deduction defines the stage where students understand and utilize properties within and among figures and can follow informal proofs. Deduction designates when students understand and can use axiom systems in proofs and can prove theorems in numerous ways, but are unable to develop or understand less conventional proofs in unfamiliar logical order. In Rigor, students can abstractly examine, compare, and contrast different axiom systems.

SOLO Taxonomy. Biggs and Collis' (1982) Structure of Observed Learning Outcomes (SOLO Taxonomy) states that students transition through a sequence of levels in the learning of algebra. In the Pre-structural phase, when engaged in a task, students are distracted or misled by irrelevant or disjointed concepts (Ansari, Lyons, van Eimeren, \& Xu, 2007; Biggs \& Collis, 1982). In the Unistructural phase, when presented a rich task involving numerous conceptual pieces and affording alternate heuristics, students focus on the one concept/heuristic with which they are most comfortable to the exclusion of others which may be more efficient, effective, or explanatory (Ansari et al., 2007; Biggs \& Collis, 1982). During the Multistructural phase, students experiencing a task can use more than one conceptual piece or heuristic, but cannot integrate them into a single, powerful, workable whole. In the Relational phase, students integrate conceptual pieces of a task into a coherent whole with structure and meaning. In the final phase, Extended Abstract, students can generalize the coherent structure, adopt novel features into the structure, modify the structure, and apply the structure in novel scenarios.

Unlike the van Hiele Model which has disjoint levels which become connected through a five-phase sequence (i.e., Inquiry/Information, Directed Orientation, Explication, Free Orientation, and Integration), the SOLO Taxonomy recognizes intermediate stages: Prestructional to Unistructural; Unistructural to Multistructural; Multistructional to Relational; and Relational to Extended Abstract.

Dienes' Learning Cycle. In a study that predicted variations in mathematics ability by investigating the correlation between basic numerical skills and early arithmetic ability, Lyons et al. (2014) recognize that there was sufficient indication that suggest that "...overall, symbolic number processing was more predictive of arithmetic ability than non-symbolic number processing, though the relative importance of symbolic number ability appears to shift from cardinal to ordinal processing" (Lyons et al., 2014, p. 1). This is supported by the work of Dienes (1971) and Dienes and Golding (1971), who propose a six-stage sequence, the Learning Cycle, through which a learner comes to understand mathematics. The first three stages (i.e., Free Play, Games, and Searching for Communalities) bear strong similarities with Piaget's descriptions of assimilation and accommodation. The last three stages include: Representation, where the learner discovers commonalities among experiences and generalizes such to novel investigations; Symbolization, where the learner need no longer experience mathematics through activities and conceptual understandings can be further investigated, applied, and extended through symbolism; and Formalization, where mathematical concepts can be interconnected into structures leading to mathematical proofs.

Intersecting Theories of Language Acquisition and Mathematics Learning

It can be argued that a number of mathematical pedagogies (e.g., dialogic teaching, talk moves, number talks, and collaborative learning) speak at least informally to the intersection of language and mathematics learning. It can be inarticulately said that some of these pedagogies argue generally that students learn through listening, communication, and interaction and that student articulations can be used as a component of assessment. In many ways, it can be seen that the Math Acquisition Framework agrees with many of these pedagogies. However, while 
these pedagogies were initially constructed upon robust theoretical frameworks, most of the discussions concerning these pedagogies have become rather informal (their foundational frameworks only infrequently mentioned) and do not connect tightly with language learning dimensions such as: Krashen's (1977, 1982) comprehensible input; Swain's (1985) comprehensible output; Selinker's $(1972,1992)$ interlanguage; and Cummins' $(1979,1984,1991)$ BICS, CALP, and CUP. Thus, the Math Acquisition Framework sought to go beyond some of these pedagogies and provide a more robust lens into student mathematical learning and language.

Through simultaneously investigating conceptual commonalities among theories associated with language acquisition and mathematics learning, Bossé et al. (2018a) and Bossé et al. (2018b) propose the Math Acquisition Framework, a four stage learning sequence to mathematics connecting definitions of the constructs from language acquisition (Cummins; 1979, 1984; Krashen \& Terrel, 1983), levels of learning/knowing (Bloom \& Krathwohl, 1956; Bruner, 1966, 1979), and theories of mathematical learning (Biggs \& Collis, 1982; Dienes, 1960, 1971; Dienes \& Golding, 1971; van Hiele, 1986). The four stages are herein only briefly defined.

Receiving Mathematics. During early mathematical learning, children begin by simply hearing teacher communication and imitating what they can. They have limited comprehension of mathematical concepts. They can only provide one or two answers to simple, predictable questions. They struggle to distinguish between valid and misleading information. They recognize predictable computations and solution strategies. While they can imitate some teacher communication, they cannot independently create their own mathematical ideas. Their mathematical communications are often mathematically and linguistically unsound and tolerated for the sake of learning.

Replicating Mathematics. In the next stage of mathematical learning, students communicate simple, conceptualized information. They have not yet constructed mathematical connections. Mathematical communications lack both linguistic precision and conceptual understanding. Students employ the limited heuristics with which they feel most familiar. They read mathematical examples and attempt to replicate in both speech and writing what they observe from the teacher. Students do not independently create novel information.

Negotiating Meaning. In this stage, speaking becomes a more primary role in student learning. Most classroom mathematics communication is comprehensible. Students understand most mathematics and employ better mathematical language. In Personal Negotiation of Meaning, they apply mathematical concepts to their own interests, but through a limited repertoire of concepts, problems, and heuristics. Mathematical concepts remain disconnected. In Interpersonal Negotiation of Meaning, students try to weave the communicated ideas of others into their own understanding. They construct intersections of ideas, but do not surpass the topics being investigated in class.

Producing Mathematics. Students in this stage have semi-professional understanding of mathematics. They are autodidactic and able to fluently communicate mathematical ideas. Mathematical concepts become interconnected and multiple mathematical representations are employed to communicate mathematical ideas. Most notably, students in this stage produce mathematics beyond that which is encountered in class and that is novel to the student.

Characteristics of the Stages of Learning. In addition to the stages developed in the Math Acquisition Framework, Bossé et al. (2018a) and Bossé et al. (2018b) suggest that other dimensions can be considered through the framework. Among others, these include: the transition from the use of social and informal language to that of academic and formal language; the transition from working in cognitively undemanding to cognitively demanding environments; the transition of the locus of activity from the teacher-centric to the student-centric; and a transition of the primary mode of communication from listening to reading and speaking to writing.

\section{Objective}

This study examines samples of student work and communication using the Math Acquisition Framework Bossé et al. (2018a) and Bossé et al. (2018b) that integrates notions from mathematics cognition and language acquisition. We examine students' mathematical understanding to determine where they are among the stages of: Receiving, Replicating, Negotiating Meaning, and Producing. Focusing attention on these elements would have long lasting implication to mathematics cognition as well as curriculum development (Kolkman, Kroesbergen, \& Leseman, 2013).

However, more than simply applying the framework to analyze some transcripts of student work, this investigation seeks to determine the framework's explanatory power. In essence, the unique factor of this study is that it both uses a novel framework and assesses whether it provides a unique window through which to consider student work.

\section{Research Methodology}

Using various mathematical topics and student learning situations, the present study seeks to explore the influence of the Math Acquisition Framework on understanding mathematics cognition. Following the opinions in the literature related to language acquisition and mathematical learning theories, a set of mathematics questions were developed geared towards unpacking student mathematical understanding, communication, and behaviors. These questions regarded topics consistent with the students' respective classroom levels.

The transcripts employed in this study were from the videotaped work of twelve students (S1-S12) from middle school through high school. These students are defined in introductions to each transcript. Teacher $1(\mathrm{~T} 1)$ is a $5^{\text {th }}$ grade teacher, Teacher 2 (T2) is a $9^{\text {th }}$ grade teacher, and Teacher 3 (T3) is an $11^{\text {th }}$ grade teacher. The researcher $(\mathrm{R})$ was a faculty member at a university in the southeastern region of the United States. These videos and transcripts were used due to their complementary nature: some were of individuals and others of groups of students; some included teacher or researcher interactions with students and others did not; and the scenarios depicted a wide range of grades and mathematical topics. Therefore, the situations were selected more so because of their differences than their similarities. The authors [or researchers] hoped that this would provide a broad investigation of student work, thinking, and experiences rather than a narrow look at similar scenarios.

To determine notions within the data and to reflect on its meaning (Creswell, 2003), a systematic process of data investigation was undertaken (Bogden \& Biklen, 2003). Video tapes were transcribed and copies of student work were merged with each transcript. Transcripts were independently analyzed to investigate student mathematical understanding, communication, and behaviors applicable to the Math Acquisition Framework (Bossé et al., 2018a; Bossé et al., 2018b). Common themes in the transcripts were characterized and labeled. Coding structures were compared, differences reconciled, and refinements were made to initial codes. Through the process of check-coding (Miles \& Huberman, 1994), researchers were able to reach consensus on the analysis of all transcripts. Narrative summaries, including illustrative excerpts from the transcripts described stages in the Math Acquisition Framework. These summaries 
were developed and validated by the researchers against transcripts and student work, and descriptive summaries were generated.

\section{Results}

The results reported below are organized by ordering consistent with the stages in the Math Acquisition Framework from Bossé et al. (2018a) and Bossé et al. (2018b). Student work and communication are analyzed through mathematical topics such as number theory (prime numbers), graphical representations, word problem, graphical analysis of asymptote, and combinatorics.

\section{Receiving Mathematics}

(Students and teacher in a $5^{\text {th }}$ grade class considering prime numbers)

T1: What are prime numbers?

S1: $\quad 1,2,3,5, \ldots$

S2: $\quad$ Not 1.1 is not prime.

S1: Why not?

S2: It wasn't on our list. [The list provided by the teacher.]

S1: Were the other numbers on our list?

S2: $\quad$ Yes, but they keep going.

T1: That is a list of prime numbers. Can you give me a definition for prime numbers?

S1: It's something about factors.

S2: Numbers with two factors. [Note the student's

omission of "distinct" from the teacher's definition.]

S3: $\quad$ Every number has two factors. 6 has 2 and 3 for

factors, and 1 and 6 for factors.

S1: That's one, two, three, four factors.

S2: $\quad$ Prime numbers are odd.

S3: $\quad 2$ isn't odd.

S2: $\quad$ Other than 2.

S1: $\quad$ And 2 has two factors, 1 and 2.

S2: $\quad 9$ is odd. How many factors does it have? 1 and 9 and 3 and 3 . It has four factors.

S3: $\quad$ But you can't tell the 3s apart. So, you count only one 3. 9 has three factors, 1, 9, and 3 .

S1: $\quad$ But that still means that it doesn't have two factors. So, 9 is not prime.

S2: What about 1. It is 1 times 1. Does it have one factor or two?

S3: I can't tell the 1s apart. So, it must have 1 factor. S1: That would mean that 1 is not prime. But it was on my list and [the teacher] did not say that it was wrong. I think she looked at my list. She did not say it was wrong. So, either my list is wrong and she didn't notice it or 1 must be prime.

In the construct Receiving, the teacher initiates and guides mathematical discussions and investigations. In the transcripts above, while student communication dominates the transcripts, the communication includes little more than three students attempting to explain and use what they had previously heard from their teacher's lectures. The students provide no novel thought or ideas. They wrestle through misconceptions. They begin by regurgitating a list of prime numbers previously provided by the teacher. They are not attempting to mimic the teacher's technique or understanding; to their best recollection, they are simply repeating a list of numbers they have heard or seen. Unfortunately, their list begins with 1. Indeed, many of the misconceptions are born from Student 2 omitting the word "distinct" from the definition.

While this transcript may be interpreted as depicting students' mathematical misunderstandings, the framework allows an alternate interpretation. Rather than focusing on either what the students do not know or misconceptions depicted in the transcripts, the framework affords the recognition that these students are, collectively, at the learn- ing stage of Receiving. They have not progressed to the stage of Replicating, where they would read mathematical texts or teacher notes and attempt to replicate ideas and techniques observed in the text and in instruction.

The content of the mathematics discussed by the students is considered socially and informally, and is lacking mathematical precision. Notably, this does not denote a lack of mathematical understanding as much as where these students are in the process of learning. It is not that they are being imprecise; they are being as precise as they possibly can in the context of the mathematics that they are learning and in their stage of development.

Notably, the last statement from Student 1 seems to imply that the student did not ask questions of the teacher. This may imply the silent period (Krashen \& Terrell, 1983), when students listen to teacher-generated mathematics, try to understand the flow of the conversation, and are mostly unable to interactively communicate mathematics. Just as Krashen (1982) proposes that comprehension precedes production for the progression of language acquisition, we observe that listening is the primary role of the student, with speaking taking a secondary and limited role. This does not imply that teachers do not use questioning techniques through which to understand student thinking and assist the student in clarifying ideas; it simply means that students have insufficient mathematical mastery to provide significant responses in return.

While the three students are actively communicating about the mathematics, the purpose of their communication is to articulate their own ideas; it is not to learn from each other. They do not recognize times of communication as opportunities for learning. They interpret learning as listening while the teacher disseminates information. While they may indeed learn though the practice of communication, they do not perceive communication as having that purpose. Nevertheless, this does not dissuade the teacher from having that purpose and attempting to pose questions and prompts that could lead to student learning.

\section{Replicating Mathematics}

Replicating 1.

(Students in a $6^{\text {th }}$ grade class considering division of fractions)

S4: To do $\frac{2}{3} \div \frac{3}{4}$, l'd use "keep-change-flip."

$\mathrm{R}$ : $\quad$ What is keep-change-flip?

S4: Our teachers taught us keep-change-flip. You keep the first fraction, change division to multiplication, and flip the second fraction. It makes $\frac{2}{3} \times \frac{4}{3}$.

R: $\quad$ Why do you do it that way?

S4: $\quad$ That's what we were told.

R: $\quad$ Can it be done another way?

S4: I think that it can be done like $\frac{2 \div 3}{3 \div 4}$. But I'm not sure if that always works.

R: $\quad$ Does keep-change-flip always work?

S4: $\quad$ I'm not sure. But that is what we are supposed to do. It must work every time, or my teachers would tell us to do it a different way.

\section{Replicating 2.}

(Students and teacher in an $8^{\text {th }}$ grade class considering the slope of a line)

R: How are you going to solve this problem?

S5: $\quad$ [Flipping pages in the book.] I'm going to find an example close to this one. [Landing on a page with a few examples from the topic.] The problem looks kinda like this one.

$\mathrm{R}$ : Which one?

S5: $\quad$ Example 3. 
$\mathrm{R}:$

ers?

S5: are up here [pointing to the first quadrant]. The others have points in different areas [meaning quadrants].

R: $\quad$ So, what are you going to do?

S5: If I take these values and plug them into the formu-

la, I should get the slope of the line. 5 minus 3 divided by 4 minus 4 is 2 divided by 0 .

R: Is that the slope of the line?

S5: Well, I think that I put the numbers in right. But I don't think that we can divide by zero. I probably used the wrong example. Let me look again.

Replicating 3.

(Student and teacher in a $9^{\text {th }}$ grade class considering the equation of a line)

T2: $\quad$ Please read the example. [The example states: The point slope form of a line is $\boldsymbol{y}-\boldsymbol{y}_{\mathbf{1}}=\boldsymbol{m}\left(\boldsymbol{x}-\boldsymbol{x}_{1}\right)$.]

S6: $\quad Y$ minus $y$ one equals $m$ times $x$ minus $x$ one.

T2: $\quad$ Can you explain to me what that means? Or what each part means?

S6: $\quad$ Well, $y$ is the $y$-variable and $x$ is the $x$-variable and $m$ is the slope.

T2: What about the other symbols?

S6: $\quad$ That's a $y$ one and an $x$ one.

T2: $\quad$ We pronounce those $y$ sub one and $x$ sub one. Sub

means subscript. Do you know what they mean?

S6: $\quad$ I think that they are values for $x$ and $y$.

T2: $\quad$ How do they differ from the $x$ and $y$, which you said were variables?

S6: $\quad$ Well both $x$ and $x$ sub one contain values. So are they both variables?

T2: If we had $\boldsymbol{y}=\mathbf{3 x}+\mathbf{2}$, what type of variable is $\boldsymbol{x}$ ?

S6: I think it is an independent variable. And $y$ is the dependent variable.

T2: $\quad$ Great. And what are 3 and 2?

S6: $\quad$ Constants.

T2: Great, again. So, can we apply that to $\boldsymbol{y}-\boldsymbol{y}_{1}=\boldsymbol{m}\left(\boldsymbol{x}-\boldsymbol{x}_{1}\right)$ ?

S6: Well, are $x$ and $x$ one - I mean $x$ sub one - inde-

pendent variables?

T2: $\quad$ What values go in for $x$ ?

S6: $\quad$ Any value in the domain.

T2: $\quad$ What values can go in to $x_{1}$ ?

S6: $\quad$ Any value?

T2: $\quad$ Well, that value is specified by the point $\left(\boldsymbol{x}_{1}, \mathbf{y}_{\mathbf{1}}\right)$.

S6: What point?

T2: $\quad$ The generic point $\left(x_{1}, y_{1}\right)$.

S6: $\quad$ Which generic point?

T2: $\quad$ Ok. Remember when you had slope intercept form

$\boldsymbol{y}=\boldsymbol{m} \boldsymbol{x}+\boldsymbol{b} ; b$ was the value of the ordered pair $(\mathbf{0}, \boldsymbol{b})$.

S6: $\quad W e l l, y e s$. But the $b$ was the $x$-intercept of the

graph. No, the $y$-intercept of the graph. Ok, ok... Never mind.

$(\mathbf{0}, \boldsymbol{b})$ is the $y$-intercept. I get it.

T2: $\quad$ So, what is the value of $b$ ?

S6: $\quad$ Whatever it is for that problem.

T2: $\quad$ So, it is not any value. It is a value specific to that problem.

S6: $\quad$ Right.

T2: $\quad$ The same for $x_{1}$ and $y_{1}$. These are values specific to the problem. While $x$ is an independent variable and can contain all values of $x_{1} x_{1}$ and $y_{1}$ hold values specific to the problem and not all values.

S6: So, what are the values for $x$ one and $y$ one in this problem?

T2: $\quad x_{1}$ and $y_{1}$ are variables for specific values. So, for instance, let's make $\left(x_{1}, y_{1}\right)$ be $(3,-2)$.

S6: $\quad$ Then, does that become $y-(-2)=m(x-3)$ ?

T2: $\quad$ Yes, but what does that mean?

S6: I'm really not sure. I guess that we can now get

$\mathbf{y}+2=\boldsymbol{m} \boldsymbol{x}-3 \boldsymbol{m}$ and that can become $\mathbf{y}=\boldsymbol{m} \boldsymbol{x}-\mathbf{3 m}-\mathbf{2}$.

T2: Ok, so what is that?

\section{S6: $\quad$ I have no clue. \\ T2: $\quad$ Do you see that it is now in slope intercept form? S6: $\quad$ No. Slope intercepts form is like $\boldsymbol{y}=3 \boldsymbol{x}+2$.}

Student 4 attempts to replicate the "keep-change-flip" heuristics previously encountered. Student 5 attempts to solve a problem by merely replicating an example from the textbook closely aligned to the problem. Notably, neither of these students possesses conceptual understanding surrounding the problem. They recognize their role as singularly that of parroting back to the teacher the ideas and techniques previously encountered. They believe that this is sufficient and that creativity and seeking for alternate heuristics are unnecessary - if not inappropriate.

Student 6 is attempting to read mathematics in order to replicate ideas, albeit with partial success. Some reading notation is mastered while other notations remain beyond understanding. Nevertheless, reading is now being supplemented to listening as a mode of learning. This reading has as a goal the understanding of the text in order to perform tasks as shown in the text, or replicate an example in the text. Importantly, Student 6 does not seem to value understanding the text as much as accomplishing the goal of solving a problem.

While the three transcripts demonstrate dissimilarities in mathematical content and student communication, far more significant commonalities exist. Students 5 and 6 demonstrate examples of incomprehensible output. Student 5 reads an example from the book, but, because the example results with a denominator of zero, considers if the student has selected an appropriate example; this student read the problem and example, but did not fully understand it. Student 6 employs terms such as variable, independent variable, domain, and generic point but these terms have incomplete meaning. The inability to adequately articulate ideas which may be understood to some level, incomprehensible output, is evidenced in the communication of Student 4's use of "keep-change-flip" and Student 5's use of "area" to mean quadrant on the Cartesian plane. Student 6 struggles to communicate ideas known regarding the use of independent variables and variables representing constants in the context of a linear function. While communication continues to develop in each of the cases, each of these three students have now surpassed the silent period.

Students 4 and 5 demonstrate articulations which remain more social in nature and Student 6 employs more academic language. Notably, this is not a function of the mathematical topic at play. For instance, Student 4 could have used academic language such as numerator, denominator, division, reciprocal, and multiplicative inverse. Student 6 demonstrates that the use of more academic language does not necessarily connote more advanced mathematical understanding.

Analysis of these transcripts reveals that these three students acquiesced to a teacher-centric locus of activity and learning. They considered the teacher's opinions and actions as sacrosanct - to be accepted, and to be replicated. Their goal as learners was simply to do as they had seen and heard from the teacher or the authoritative textbook selected by the teacher. This is evidenced by Student 4 stating, "That's what we were told... [T] hat is what we are supposed to do. It must work every time, or my teachers would tell us to do it a different way", Student 5 trying to replicate what s/he read in the textbook, and Student 6 immediately adopting the teacher's vocabulary in his/her communication (e.g., "y one and an $x$ one" $\Rightarrow$ " $y$ sub one and $x$ sub one" $\Rightarrow$ " $x$ and $x$ one - I mean $x$ sub one", "generic point", and "slope intercept form").

Notably, although discourse among students is not repre- 
sented in the transcripts, the communication gains mathematical precision and maturity over the Receiving stage. Nevertheless, mathematical language, interpretation, and nomenclature are all still lacking. Thus, remaining mostly informal, the discussions are trending toward less formal and slightly more focused toward learning than simply communication. While Students 4,5 , and 6 are each actively communicating with the researcher or teacher about the mathematics, they perceive the purpose of their communication as assessment rather than learning. The communication, via questioning or activities, is generated by the adult not the student. Nevertheless, contextualized communication is becoming more mathematically focused and precise.

Students 4, 5, and 6 are beyond the stage of simply Receiving by listening to teacher lectures. While listening remains a significant aspect of learning, reading takes on an increasing role. However, they are not yet fully Negotiating Meaning regarding the mathematics that they are learning.

\section{Negotiating Meaning}

\section{Personal 1.}

(Student in a $10^{\text {th }}$ grade class considering algebra applied to purchasing a car)

S7: $\quad$ My Dad says that he will either buy me a brand new car when I turn 16 or he will buy me two six year old cars in a row. I mean, he'll buy me a six year-old car when I turn 16 and, when that one dies, he'll buy me another six year-old car.

R: What are you going to choose?

S7: I've gotta look at it. I need to figure out how long a car lasts. And how many miles a six year-old car has. guess I would also like to know who owned the cars.

$\mathrm{R}: \quad$ Anything else?

S7: $\quad$ Wow. So much more. I need to know about mechanical costs and warrantees. I know that new cars are pretty covered. And they shouldn't break down much. But they only last so long. But I like new cars. I know how I drive and that I can keep it good. I will know all the problems it has.

R: $\quad$ You have been thinking about this a lot. How are you going to figure this all out?

S7: Well I think that I can set up some equations to investigate it more. I'm not yet sure how. But I want to make the right decision.

R: $\quad$ Do you think that the math you have learned so far has given you the tools to figure this one out?

S7: I'm not sure yet. But I'm gonna try. I'll look more in the book if I have to.

While Student 7 lacks some necessary mathematical knowledge in the context of his/her investigation, this student is Personally Negotiating Meaning in mathematics by applying mathematics to his/her own life. The student is attempting to integrate what s/he discovers into his/her existing framework of knowledge. While mathematical learning is certainly growing, this student's mathematics exhibits both voids and disconnectedness. Nevertheless, the purpose for the mathematical learning in this context is both personal and pragmatic in nature. While not to the exclusion of listening to lectures, Student 7 now routinely investigates and accesses written mathematics and explanations. Learning is progressing from auditory to written form, with fewer instances of either incomprehensible input and output.

Student 7's communication is directed toward the adult figure. The primary purpose of the communication is pragmatic: to fulfill his/her personal interests and accomplishing a task. While the purpose may be to learn, it is not to collaborate in learning with others. The mathematics communication is becoming increasingly academic, albeit in the direction selected by the student more so than by the teacher. Casual conversation without the purpose of solving the task at hand has increasingly less value. Moreover, the locus of activity is shifting from centering on the teacher to the student's own interests and motivation for learning.

Student 7 has not yet progressed to Intrapersonal Negotiating Meaning, where students discuss mathematics in order to collaboratively learn mathematics. S/he does not mention collaborating with other students to learn and may not yet value this interaction.

Personal 2.

(Student in $X^{\text {th }}$ grade investigating factoring quadratics.)

R. If $a x^{2}+b x-c=(p x+q)(r x-s)$, then

$a x^{2}-b x-c=(p x-q)(r x+s)$. What do you think?

S8: Well, I need to try some examples. I guess we can start with anything. How about $3 \boldsymbol{x}^{2}+5 x-7$ ? That would mean that $3 x^{2}-5 x-7$ should also be factorable.

R: $\quad$ I did not use the word factorable.

S8: $\quad$ No, but $(p \boldsymbol{x}+q)(\boldsymbol{r} \boldsymbol{x}-\boldsymbol{s})$ is factored. So, it means that the quadratics are factorable. Is that correct? (No response from the researcher.) I think it's right. I guess I need to factor $3 x^{2}+5 x-7$ and $3 x^{2}-5 x-7$. (S8 makes numerous attempts to factor both quadratics.) I don't know what to do. I can't factor either of these. I may need to use the

quadratic formula. (S8 writes out: $\frac{-b \pm \sqrt{b^{2}-4 a c}}{2 a}$.) So, $\frac{-5 \pm \sqrt{5^{2}-4 \cdot 3 \cdot 7}}{2 \cdot 3}=\frac{-5 \pm \sqrt{25-84}}{6}=\frac{-5 \pm \sqrt{-59}}{6}$ that is $\frac{-5 \pm \sqrt{5 \cdot-4 \cdot 3 \cdot 7}}{6}=\frac{-5 \pm \sqrt{25-84}}{6}$. Um? We can't take the square root of a negative number. Um? Well, we $\frac{-5 \pm i \sqrt{59}}{6}$ Well, we can. We can maybe do something like 6 . And the other quadratic would give us: ... $\frac{-5 \pm \sqrt{109}}{6}$. That did not get me close to $(p \mathbf{x}+q)(r \mathbf{x}-\mathbf{s})$ or $(p \mathbf{x}-q)(r \mathbf{x}+\mathbf{s})$.

R: $\quad$ So, what are you going to do?

S8: Well, I can't tell if it is true yet until I can factor some quadratics. Um? And if I start with a quadratic, I can't always know if it is factorable. Um? But it said that it is factorable. But $3 x^{2}+5 x-7$ isn't factorable... Um? I don't think that I understand.

R: $\quad$ (About to ask a question...)

S8: $\quad$ Wait. I think that I should start with a quadratic that I know is factorable.

R: $\quad$ How would you do that?

S8: I think that I can work backwards. If I start with $(p \boldsymbol{x}+q)(r \boldsymbol{x}-\mathbf{s})$ like $(2 \boldsymbol{x}+3)(4 \boldsymbol{x}-5)$, then, $\quad(2 x+3)(4 x-5)=\cdots=8 x^{2}+2 x-15$. So, $(2 x-3)(4 x+5)=\cdots=8 x^{2}-2 x-15$. Hey, it worked!

R: $\quad$ So, what did you not initially understand?

S8: $\quad$ We need to start with a factorable quadratic. $\mathrm{R}$ : What if the quadratic is factorable in the reals, but not in the rationals, or even in the complex?

S8: I would need to check, but that might work. I would have to look at my work.

R: $\quad$ We can hold off on that for now. But let's go one more step. If $a x^{2}+b x-c$ and $a x^{2}-b x-c$ are factorable,

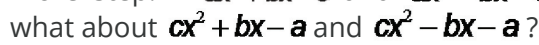

S8: I'm gonna guess first, then l'll check one out. I just gonna guess that $\boldsymbol{c x}^{2}+\boldsymbol{b x}-\boldsymbol{a}$ would be something like $(\boldsymbol{q} \boldsymbol{X}+\boldsymbol{p})(\mathbf{s} \boldsymbol{x}-\boldsymbol{r})$. You know, writing my factors backwards. That way, just like $p$ and $r$ works with a like before. I'll have to check this out. I know that I could start with $15 x^{2}+2 x-8$, but I need to make sure that everything works. If it does, that would be really cool. 
R: $\quad$ What would be?

S8: It would mean that, if $\boldsymbol{a} \boldsymbol{x}^{2}+\boldsymbol{b x}-\boldsymbol{c}$ is factorable, then $a x^{2}-b x-c, c x^{2}+b x-a$, and $c x^{2}-b x-a$ are all factorable.

Notably, Student 8 communicates more with him/herself than with the researcher. S8 looks to past work to further understand immediate questions. S8 is Personally Negotiating Meaning in mathematics by working independently to understand the mathematics at hand. S8 investigates and accesses written mathematics and explanations, even when some of those ideas were previously proposed by him/herself. As with S7, learning is progressing from auditory to written form, with fewer instances of either incomprehensible input and output.

Student 8's communication is primarily rhetorical in nature - more directed to self rather than the researcher. The mathematics communication is academic and self-directed. The locus of activity is shifting learning from self. In this brief and restricted scenario, there is no evidence that Student 8 has progressed to Intrapersonal Negotiating Meaning, where students discuss mathematics in order to collaboratively learn mathematics.

Interpersonal.

(Students in an $11^{\text {th }}$ grade class considering rational functions)

S9: $\quad$ I'm trying to figure out if graph can cross an asymp-

tote.

S10: We know that it can't cross a vertical asymptote. That is where the function is undefined.

S9: $\quad$ Right. But can a function cross another kind of asymptote?

S11: $\quad$ You mean like a horizontal or slant asymptote?

S9: $\quad$ Or even a curved asymptote.

S10: What if we start with something kinda obvious? What if we have vertical asymptotes at -2 and 2 with a $x$-intercept at 0 . Then the graph would make an " $\mathrm{S}$ " between the asymptotes.

S11: $\quad$ But that is only when we have no other roots between those asymptotes... And if the root is not an even root; and even roots would give us a bounce. But, where is the horizontal asymptote?

s9: I don't think it matters. Wherever the horizontal asymptote is, no matter how high or low, the graph will "S" through that area and go from negative infinity to positive infinity. So, it must go through the asymptote. So, that answers my question.

S11: $\quad$ So, that must hold for slant and curved asymptotes for the same reason.

S10: Ok. But that only deals with the case of between asymptotes. What about outside of asymptotes? Can a graph cross an asymptote outside of vertical asymptotes?

59: I don't know. Is there a way we can test it?

S11: We could put functions in the calculator. But that could take forever.

S10: We probably need to think about it - before we just start plugging in functions. We could construct a rational

function to do what we want. For instance $\overline{\boldsymbol{x}(\boldsymbol{x}+1)}$ will give us a vertical asymptote at 0 and -1 . So, we could stay to the right $\frac{(x-2)(x-3)}{x(x+1)}$

of 0 . What happens if we have something like $\quad x(x+1)$ That would put both roots to the right of the vertical asymptotes.

S9: $\quad$ And a horizontal asymptote at 1.

S11: Let's graph it. [Uses a graphing calculator.]

S10: $\quad$ Maybe we just got lucky, but the graph does come down from the vertical asymptote at 0 hit the $x$-axis twice and then go back up to 1 .

S11: Maybe we got lucky in other ways too. I think that if we have any two real roots (they could be the same) on the right of 0 , the graph will still come down and cross the asymptote before coming back to it.

Students 9, 10, and 11 are intimately involved in discourse. Their mathematical interaction is increasingly academic in nature and purposed in learning. They recognize that they are learning from each other. While it can be argued that some of the previous transcripts depict students learning through communication, these students now recognize that learning occurs in this environment and communication has the purpose of learning. The students each recognize that the other students have important ideas to contribute to the group learning. Additionally, the students take the responsibility for their own learning; the locus of teaching and learning is no longer teacher-centric.

The mathematics discourse is becoming refined and precise, with little evidence of incomprehensible input or output. When they employ more casual language (e.g., "The graph would make an " $\mathrm{S}$ " between the asymptotes."), it is because they have not been previously introduced to more formal appropriate language. Nevertheless, they communicate the notion in a manner which all understand in the context of the problem - an interlanguage. They listen to the ideas, interpret them in the context of the investigation, use them to modify their own understanding, and proffer their refined ideas.

Significant within the transcripts, Students 9, 10, and 11 are looking at the mathematics that they have previously encountered. They are making connections among previously disconnected ideas. However, they have not created mathematical ideas both new to them and beyond what they had previously encountered. Therefore, they are solidly ensconced in Negotiating Meaning and have not progressed to Producing Mathematics.

\section{Producing Mathematics}

(Student and teacher in an $11^{\text {th }}$ grade class considering permutations and combinations)

T3: I am curious, why are you doing this like this?

S12: It's easier.

T3: How?

S12: It wants me to calculate ${ }_{20} \boldsymbol{C}_{5}$. But that is the same as ${ }_{20} C_{15}$. And I just like my larger number to be the first factorial in the denominator.

T3: $\quad$ How do you know that those are equal?

S12: Well, it just makes sense. If $r$ is 5 , then $n$ minus 5 is 15. And, if $r$ is 15 , then $n$ minus 15 is 5 . So, either way, I get 5 ! $\times 15$ ! in my denominator.

T3: That is interesting. I don't think that I have ever thought about it that way before. It is pretty slick. It's not in the book. Did you Google that?

S12: $\quad$ Nope. I just thought about it some. It's just fun.

T3: Do you think that you can write that into a theo-

rem?

S12: Well, since ${ }_{20} C_{5}={ }_{20} C_{15}, I$ think that I could write it like ${ }_{n} C_{r}={ }_{n} C_{n-r}$. That would make ${ }_{n} C_{r}={ }_{n} C_{n-r}=\frac{n !}{r !(n-r) !}$. Yup, that works.

Student 12 is producing mathematics that is new from his/ her perspective. While this mathematics is well known in the field, it is novel to this student and beyond anything that $\mathrm{s} /$ he has experienced in learning activities to which s/he was exposed. The student's mathematical language is elevated, precise, and accurate - academic language, devoid of examples of incomprehensible input and output. His/her communication often takes written form in order to effectively capture and communicate rich mathematical ideas. The locus of learning is now squarely student-centric and abstracted from the teacher. Altogether, this student can be placed in the stage of Producing Mathematics. 


\section{Discussion}

The transcripts demonstrate cases in each of the stages of Receiving, Replicating, Negotiating Meaning, and Producing mathematics. Notably, transitions can be recognized through these transcripts of: Language from social and informal to academic and formal; Cognitive Level from undemanding to demanding; Locus of Activity from the teacher to the students; and Primary Mode of Communication from listening to reading and speaking to writing. Furthermore, additional dimensions regarding interlanguage are herein discussed. These are all consistent with the Math Acquisition Framework being investigated (Bossé, et al., 2018a; Bossé, et al., 2018b).

\section{Interlanguage}

More precisely, we can recognize that the aspects of language are at play among the students reported above. For instance, Students 1-6 clearly struggle to understand some aspects of the previous class instruction. Some notions, although possibly seemingly well explicated in class, may have been only partially understood at the time; other concepts may have simultaneously been beyond the grasp of the students. This is an example of comprehensible input (Krashen, 1977, 1982; Krashen \& Terrell, 1983). However, while not necessarily fully understanding all the mathematics at hand, fewer among the Students 7-12 seem to have had mathematical concepts out of their grasp. In respect to comprehensible output (Krashen, 1977, 1982; Krashen \& Terrell, 1983), or ideas that students partially understand but cannot sufficiently communicate, it is apparent that Students1-6 struggle to communicate mathematical ideas. This is far less the case with Students 7-12.

The sequence of transcripts and the idiosyncratic nature of student language demonstrate the evolution of Selink er's $(1972,1992)$ interlanguage. In attempting to communicate mathematical ideas, most students construct their own versions of mathematical language. Notably, the students in the earlier stages occasionally employ language and ideas that are incongruous with the mathematical topic under consideration. Students in the later stages employed language and ideas that are better connected to the topic in question, while revealing mathematical connections they are making.

In summary, comprehensible input and output diminish throughout a student's learning in two ways: longitudinally throughout a student's mathematical academic development and iteratively each time new mathematical topics are encountered. Additionally, the student's mathematical interlanguage continues to evolve and be refined, to finally approach proficiency.

\section{Language}

The communication among Students 1-3 indicates that they are basing all of their knowledge on what they heard (or misheard) from the teacher. While the students attempt to use the best language and ideas they can in order to articulate their thoughts, their communications are social, informal, and mathematically imprecise. Student 4 uses the informal language of "keep-change-flip" in an attempt to communicate a more advanced mathematical concept. Both Student 5 and Student 6 are becoming more focused on reading mathematics; of necessity, this implies transitioning to more academic use of language particularly regarding students receiving information.

Students 9-11 are beginning to use more precise mathematical language in their communications. Apart from defining the local behaviour of a graph as an " $\mathrm{S}$ ", they employ mathematical terms in correct contexts. Their communi- cation is less social and more academic in nature.

Altogether, the progress through the framework depicts language initially being social and informal and becoming more academic and formal. Language initially tolerated in early stages becomes replaced by sophisticated structures and ideas.

\section{Cognitive Level}

It is easy to misconstrue the level of mathematics with the cognitive level used by a student in solving a problem. Examples, applications, or investigations of relatively elementary mathematics can be posed in ways that require significantly higher levels of cognition. The topic of mathematical investigation does not equate to cognitive levels; the environment through which the student is experiencing the topic connotes the cognitive level.

The transcripts demonstrate that, independent of the level of the mathematical topic under investigation, Students 1-12 progress from tasks requiring very low cognitive load (i.e., list prime numbers) to a task - albeit self-imposed - of high cognitive load (i.e., invent a new theorem). It is yet unknown, however, if students progress through the framework by experiencing more cognitively demanding tasks or if they cannot accomplish more cognitively demanding tasks until they are sufficiently cognitively mature for such.

\section{Locus of Activity}

A progression from teacher-centric to student-centric activity can be recognized through the transcripts. While the transcripts from Student 1-3 demonstrate students' work with minimal input from the teacher, the mathematical task investigated by the students was developed by the teacher. Thus, locus of activity is deemed to be teacher-centric. Students 9-11 are investigating a problem with little or no teacher input. They are relying on the power of the group of students to ascertain answers. This is deemed student-centric. Student 12 provides an exemplar of the most extreme case of student-centric work. Student 12 develops a new mathematical theorem independent from the teacher and text he has experienced.

The progression from teacher-centric presentation of information to student-centric activity underpins that knowledge transfer is not the primary responsibility of the teacher; rather, knowledge construction, to a greater extent, depends on student interaction. Therefore, students need additional opportunities to interact and collaborate with others. Noting that Student 11 developed a new mathematical theorem independent from teacher direction may argue that students need additional opportunities to learn independently through substitute approaches that enhance creative thinking. These can be integrated with cooperative learning. In effect, a paradigm shift is needed to move education from an instructional paradigm to a learning paradigm.

\section{Primary Mode of Communication}

As with other dimensions, a transition can be seen from the lowest to the highest stages in respect to the primary role of student communication. In the earliest stages, Students 1-3 are primarily listening and minimally responding to the teacher. In more central learning stages, Students 4-7 and 8-11 are more focused on reading mathematical texts and speaking with other students. In the last stage, Student 12 communicates through writing.

Both in the preceding transcripts of student work and in relevant literature, there is evidence that language can act as an instrument that can mediate thought processes in a variety of ways ranging from instructional practices to conceptual learning. From the perspective of 
language acquisition, the progression of primary mode of communication being listening $\rightarrow$ speaking $\rightarrow$ reading $\rightarrow$ writing is quite obvious. More precisely, the pattern may be listening $\rightarrow \underset{\text { reading }}{\text { speaking }} \rightarrow$ seading $\rightarrow$ speaking $\rightarrow$ witing. However, it should be recognized that this progression holds for mathematics learning as well, when mathematical fluency is the educational goal.

\section{Beyond Recognizing Student Errors}

Many frameworks can determine the existence of mathematical and linguistic errors as students perform, and communicate about, mathematics (e.g., Adu-Gyamfi, Bossé, \& Chandler, 2015; Adu-Gyamfi, Stiff, \& Bossé, 2012; Brown, Bossé, \& Chandler, 2016). While is this valuable? First, it may do little to explain from whence these errors arise. Second, focusing singularly on mathematical errors may paint an overly sombre representation of student understanding and learning. Third, focussing on errors may not provide suggestions of instructional techniques to help students overcome erroneous thinking. Absent from many frameworks is what students can do and what they understand.

The Math Acquisition Framework investigated in this study determines in which stage of mathematical learning a student presents himself. In return, quite possibly, the most valuable aspect of using the framework may be in recognizing that particular strengths, weaknesses, and styles of communication - among numerous other factors - present themselves in each level of learning. Thus, mathematical performance and linguistic use can be seen as naturally embedded within a stage of learning rather than as types of errors. Within stages of learning, these behaviors can be recognized as natural components of the learning process. This perspective is made available through the framework's connections with language acquisition. In the learning of a second language, grammatical errors and linguistic misuse are recognized as natural, experiential components of learning and not singularly as errors in understanding.

Another aspect of using the Math Acquisition Framework is its independence of stages of learning to the mathematical topic. It is not the elevation of the mathematical topic that determines whether or not the student is in an experience determined to be either cognitively undemanding or cognitively demanding. Rather, it is the learning activity that determines this.

The Math Acquisition Framework (Bossé, et al., 2018a; Bossé, et al., 2018b) may be iterative as new ideas are encountered. For instance, when an algebra student first sits in a calculus class, he may immediately be bombarded with novel ideas that are possibly - initially and temporarily - beyond his grasp (comprehensible input). He may sit silent while attempting to assimilate what the teacher is reciting (the silent period). When he begins to communicate calculus ideas, his ideas may not be well articulated (comprehensible output). He may begin communicating novel ideas through vocabulary and ideas previously understood in algebra (interlanguage). And so forth. Thus, the framework can be recognized as either a sequence of stages to be traversed once in a learner's lifetime of mathematical learning or as an iterative process when new mathematical topics are encountered. However, when the framework acts iteratively, the spiral of learning gets tightened and many notions need not be retaught and relearned.

A significant question remains: Is the Math Acquisition Framework a process through which students naturally progress or a process toward which education should direct learning activities and experiences? The authors of this study believe that both are the case. Some implications of this follow.

\section{Implications}

The authors strongly caution against a misinterpretation of the Math Acquisition Framework. While it can be employed as a component of assessment, it should not be singularly considered a measure of mathematical understanding commensurate with the stage into which a student falls. Rather than determining a level of mathematical knowledge, the framework represents stages in the learning of mathematics: how math is learned rather than how much is learned. Understanding mathematical learning through a student's mathematical communication and through the lens of the Math Acquisition Framework can assist teachers in assessing a student's mathematical understanding. This is particularly valuable when students are experiencing comprehensible input, comprehensible output, and interlanguage, and thereby when students' articulations may be most difficult to understand and discern for mathematical comprehension. The researchers argue that viewing mathematical learning as a series of stages similar to those involved in language acquisition has several important implications for mathematics education. Understanding these stages can facilitate and inform both the student's and the teacher's role in learning. Particularly, the teacher should see that a student progressing through the stages of the framework includes a transition from a teacher-centric experience to that of a student-centric experience. Thus, a teacher needs to develop and sequence activities to accomplish this growth in the student.

Teachers also need to provide a sequence of activities wherein students experience increasingly cognitively demanding activities. It may well be that many teachers underestimate the ability and willingness of students to persevere through cognitively demanding tasks. It may also be that teachers equate higher cognitive demand with progressing through sequenced curricular materials. These notions should be challenged.

Teachers need to employ activities that cause the students to communicate with other students. Students need the opportunity to wrestle with ideas. Learning occurs through this wrestling.

Some natural questions can be raised. While it is obviously possible to show students mathematical ideas which far exceed their capacity to grasp, is it valuable to teach slightly above their level to promote progress through the Math Acquisition Framework and learning? This is not yet known. Learning is a complex activity in which there is an element of progressive levels involved. Having students encounter mathematical ideas that exceed their immediate capacity to grasp has several implications. First, might this promote procedural learning rather than conceptual understanding? How might that positively or negatively affect growth toward mathematical fluency? If emersion in a second language environment is considered an effective vehicle for learning, could student encounters with more advanced concepts be equated to emersion?

\section{Conclusion}

Altogether, investigating mathematical learning theories through the lens of language has led to the development of a novel, synthesized sequence of mathematical learning constructs which include: Receiving, Replicating, Negotiating Meaning, and Producing. Understanding the stages of mathematical learning is essential for educators who are attempting to create curricula and instructional experiences commensurate with a student's level of mathematical understanding. Altogether, many of the findings within this investigation lead to additional hypotheses and questions that have only been proposed herein. It is hoped that future research attempts to answer these questions and verify or disprove these hypotheses. 


\section{Further Research}

The present study examined a novel framework of mathematical learning through selected samples of student work. One clear path for further research is to apply this framework to a greater variety of learning contexts, including longitudinal studies of the development of mathematical knowledge. This study also focused on the parallels between linguistic comprehension and production and Cummins' model of second language acquisition with mathematical learning. Several other parallels between the two remain to be explored, including whether or not we can identify a code similar to interlanguage in the realm of mathematics and to what extent Vygotsky's $(1986,1978)$ theories of sociocultural learning and language acquisition may also inform the learning of mathematics.

This study did not investigate the factor of age in mathematical learning; but, given that it has been proposed that there exists a critical period for language development beginning with the first few years of life and that the window of opportunity for learners to become fluent in a second language is limited (Lenneberg 1967, 1975), could a similar critical period exist for the learning of mathematics? If so, does this mean that mathematics instruction and learning should be strongly emphasized in the earliest ages of a child's development, and that emphasis should continue through puberty? In a related question, if students usually take five to seven years to gain second language fluency, might there exist a minimal time span necessary for most students to gain mathematical fluency? Since mathematics is topical (some may argue, sequentially topical) and ideas grow in sophistication as students progress through them, will that mean that this minimal time frame applies to every topical idea or does it depend on the type of topic being treated? Both of these ideas, if borne out by further research, would have significant implications for mathematics curricula.

\section{References}

Adu-Gyamfi, K., Bossé, M. J., \& Chandler, K. (2015). Situating student errors: Linguistic-to-algebra translation errors. International Journal for Mathematics Teaching and Learning. Retrieved from http://www. cimt.org.uk/journal/bosse6.pdf

Adu-Gyamfi, K., Stiff, L., \& Bossé, M. J. (2012). Lost in translation: Examining translation errors associated with mathematics representations. School Science and Mathematics, 112(3), 159-170.

Ansari, D., Lyons, I. M., van Eimeren, L., \& Xu, F. (2007). Linking visual attention and number processing in the brain: The role of the temporo-parietal junction in small and large symbolic and nonsymbolic number comparison. Journal of Cognitive Neuroscience 19(11), 1845-1853.

Biggs, J. B., \& Collis, K. F. (1982). Evaluating the quality of learning - The SOLO taxonomy. New York, NY: Academic Press.

Blomert, L., \& Froyen, D. (2010). Multi-sensory learning and learning to read. International Journal of Psychophysiology, 77(3), 195-204.

Bloom, B. S., \& Krathwohl, D. R. (1956). Taxonomy of educational objectives: The classification of educational goals, by a committee of college and university examiners. Handbook 1: Cognitive domain. New York, Longmans.
Bogdan, R. C., \& Biklen, S. K. (2003). Qualitative research for education: An introduction to theories and methods (4th ed.). Boston: Allyn and Bacon.

Bossé, M. J., Bayaga, A., Fountain, C. A., Lynch-Davis, K., Preston, R., \&, Adu-Gyamfi, K. (2018a). Fraction learners: Assessing understanding through language acquisition. International Electronic Journal of Elementary Education, 11(2), 113-124. https://www. iejee.com/index.php/IEJEE/article/view/649/374

Bossé, M. J., Ringler, M., Bayaga, A., Fountain, C.A., \& Slate Young, E. (2018b). Acquiring math: Connecting math learning and second language acquisition. International Journal of Mathematics Teaching and Learning, 19, 223-252. https://www.cimt.org.uk/ ijmtl/index.php/JJMTL/article/view/151

Brown, M., Bossé, M. J. \& Chandler, K. (2016). Student errors in dynamic mathematical environments. International Journal for Mathematics Teaching and Learning. Retrieved from http://www.cimt.org.uk/ journal/bosse8.pdf .

Bruner, J. S. (1966). Toward a theory of instruction. New York: Norton.

Bruner, J. S. (1979). On knowing. Cambridge, MA: Belknap Printing.

Cabrelli Amaro, J., Flynn, S. \& Rothman, J. (2012). Third language acquisition in adulthood. Philadelphia/Amsterdam: John Benjamins.

Chomsky, N. (1965). Aspects of the Theory of Syntax. Cambridge, MA: MIT Press.

Creswell, W. J. (2003). Research Design: Qualitative, quantitative and mixed methods approaches. (2nd ed.). London: Sage Publications.

Cummins, J. (1979). Cognitive/academic language proficiency, linguistic interdependence, the optimum age question and some other matters. Working $P a-$ pers on Bilingualism, 19, 121-129.

Cummins, J. (1984). Bilingualism and special education: Issues in assessment and pedagogy. Clevedon, England: Multilingual Matters.

Cummins, J. (1991). Language development and academic learning. In L. Malavé \& G. Duquette (Eds.) Language, culture and cognition. (pp. 161-175). Clevedon, England: Multilingual Matters.

Dienes, Z. P. (1960). Building up mathematics. London, England: Hutchinson Education Ltd.

Dienes, Z. P. (1971). An example of the passage from the concrete to the manipulation of formal systems. Educational Studies in Mathematics,3 (3/4), 337-352.

Dienes, Z. P. \& Golding, E. W. (1971). Approach to modern mathematics. New York: Herder and Herder Co.

Kolkman, M.E., Kroesbergen, E.H., \& Leseman, P.P.M. (2013). Early numerical development and the role of non-symbolic and symbolic skills. Learning and Instruction, 25, 95-103.

Krashen, S. (1977). Some Issues Relating to the Monitor Model. In H. D. Brown, C. Yorio \& R. Crymes (Eds.) Teaching and Learning English as a Second Language: 
Trends in Research and Practice. (pp. 144-158) Washington: TESOL.

Krashen, S. D. (1982). Principles and practice in second language acquisition. Oxford: Pergamon.

Krashen, S. D., \& Terrell, T. (1983). The natural approach: Language acquisition in the classroom. London: Prentice Hall Europe.

Lenneberg, E. H. (1967). Biological foundations of language. New York: John Wiley and Sons.

Lenneberg, E. H. (1975). The concept of language differentiation. In E. H. Lenneberg \& E. Lenneberg, (Eds), Foundations of language development: A multidisciplinary approach (Vol 1). New York, NY: Academic Press.

Lyons, I. M., Price, G. R., Vaessen, A., Blomert, L., Ansari, D. (2014). Numerical predictors of arithmetic success in grades 1-6. Developmental Science, 17, 714-726.

Miles, M. B. \& Huberman, M. N. (1994). Qualitative data analysis: An expanded sourcebook. Thousand Oaks, CA: Sage.

Moschkovich, J. 2005. Using two languages when learning mathematics. Educational Studies in Mathematics, 64, 121-144.

Selinker, L. (1992). Rediscovering interlanguage. London: Longman.

Selinker, L. (1972). Interlanguage. International Review of Applied Linguistics, 10, 209-231.

Swain, M. (1985). Communicative competence: some roles of comprehensible input and comprehensible output in its development. In S. Gass, S. and C. Madden, (Eds.), Input in Second Language Acquisition. Rowley, MA: Newbury House.

Swain, M. and Lapkin, S. (1995). Problems in output and the cognitive processes they generate: A step towards second language learning. Applied Linguistics, 16, 371 . 391.

Thompson, D. \& Rubenstein, R. (2014). Literacy in language and mathematics: More in common than you think. Journal of Adolescent and Adult Literacy, 58(2), 105-108.

Van Hiele, P. M. (1986). Structure and insight: $A$ theory of mathematics education. Orlando, FL: Academic Press.

Vygotsky, L. S. (1978). Mind in society. Cambridge, MA: Harvard University Press.

Vygotsky, L. S. (1986). Thought and Language. A. Kozulin, (Ed.). Cambridge, MA: MIT Press 